\title{
XI. The sparking distances between plates for small distances
}

\section{Robert F. Earhart}

To cite this article: Robert F. Earhart (1901) XI. The sparking distances between plates for small distances, Philosophical Magazine Series 6, 1:1, 147-159, DOI: $10.1080 / 14786440109462598$

To link to this article: http://dx.doi.org/10.1080/14786440109462598

曲 Published online: 08 Jun 2010.

Submit your article to this journal $ऍ$

山 Article views: 14

Q View related articles $\square$

Citing articles: 33 View citing articles $\sqsubset$ 
Although in the above examples of non-electrolytic mixtures and solutions there seems to be some connexion between the values of $m$ in the formula for the temperature-variation of the viscosities of two liquids, and its value in the formula for the viscosities of mixtures of the two, the number of instances is too sinall to warrant a general conclusion being drawn. In the case of the electrolytic solution $(\mathrm{NaCl})$ the values of $m$ for the mixtures at different temperatures vary greatly from one another, although the values in the temperature formula are practically identical. Possibly the magnitude of the heat of solution of $\mathrm{NaCl}$ places it outside the class of simple mixtures considered in what precedes.

The result of this investigation may be summed up as follows :-

(1) No one of the three theoretical formulx (1), (2), (3) represents the viscosity of a mixture with sufficient closeness.

(2) The empirical formula $\left(\frac{1}{\eta}\right)^{m}=v_{1}\left(\frac{1}{\eta_{1}}\right)^{m}+v_{2}\left(\frac{1}{\eta_{2}}\right)^{m}$ with a suitable value for $m$ gives a satisfactory representation.

(3) It leads also to Slotte's formula for the variation of viscosity of a liquid with temperature.

XT. The Sparking Distances between Plates for small Distances. By Robert F. Earhart*

HISTORICAL.-Previous to 1860 , several series of measurements on the difference of potential required to cause a spark to pass between plates separated by a stratum of air, had been made. These earlier experiments by Volta (Identita, p. 53), Riess (Pogg. Ann. vol. xl. p. 333), and others possess little more than historic interest, the means at their disposal for measuring differences of potential having been unreliable. The first trustworthy series of measurements were those performed in 1860, under the direction of Sir William Thomson (now Lord Kelvin) (Electrostatics and Magnetism, p. 250). In the series of measurements referred to, the plates were separated by known distances, the distances being determined by a micrometer-screw. The potentials required to cause a breaking down of the intervening dielectric were measured by the absolute electrometer. The results obtained show that the difference in potential necessary to break down the medium is not directly proportional to the thickness of the separating medium. This has been amply verified by other observers. Various * Communicated by the Author.

L 2 
theories have been offered to explain this phenomenon : among them the hypothesis that a certain amount of energy is necessary to tear asunder an air-film which may surround the surfaces in question, the assumption being that, in the neighbourhood of bodies, the air possesses a more or less definite structure, and that in this condition the dielectric properties of air differ from those which it possesses in the ordinary gaseous form. A much more complete series of observations on the spark potential were undertaken by Dr. Liebig in 1887 (Phil. Mag. vol. xxiv. p. 106). In these experiments the distances were varied from $\cdot 0066 \mathrm{~cm}$. to $1 \cdot 144 \mathrm{~cm}$. The methods of measuring both distances and difference of potential were similar to those employed by Lord Kelvin.

object.-It seems desirable to obtain measurements for very thin strata of the dielectric, and if possible to ascertain the potential necessary to break down the air-film itself. To accomplish this, a much more delicate method of measuring the thickness of the separating medium is imperative if the limiting value is to be approached. The modern form of the interferometer is particularly suitable for measuring small distances, and may be readily adapted to this experiment. The conditions to be fulfilied are extremely simple : we are required,

1st: To measure a small distance accurately ;

2nd: To measure differences in potential accurately.

To fulfil the first condition. Consider two plane paralleI surfaces in contact. Let one of them be rigidly attached to a fixed support. Let the other be mounted on a movahle carriage which bears one of the mirrors of an interferometer. Upon separating the surfaces, a succession of fringes (preferably circular) will move across the field of view. $\mathrm{B}_{y}$ counting the procession of fringes, the distance through which the carriage is moved, and therefore the distance of separation of the plates, will be given directly in terms of wave-lengths of light.

It may readily be shown that a passage of one fringe across the field corresponds to the movement of the carriage through a distance of half a wave-length. Again, since fractions of fringes can be measured readily to one-tenth of a fringe, and since the wave-length of sodium light is approximately equal to $59 \mu$, we shall be enabled to measure distances of $03 \mu$ if desired. Any departure in the motion of the movable plate from a plane not parallel to itself $n$ ill be indicated by the appearance of the circular fringes.

Experience bas shown that it is practically impossible for 
parallel plates to be brought into contact thronghout the entire extent of the surfaces. This is probably due to the existence of a gaseous film surrounding the surfaces. In exerting a pressure sufficient to squeeze out this last vestige of the air, strains are introduced which destroy the parallelism of the plates. Apart from this the electrical conditions render it advisable that one surface be convex.

Description.-In the experiment here described, one of the surfaces is convex, the other plane. In the accompanying diagram, let " $\mathrm{D}$ " be the fixed body, rigidly attached to a firm support A. This fixed body consisted of a steel bicycle ball, heavily nickel-plated, and $2.52 \mathrm{~cm}$. in diameter. This was carefully insulated from the support, and connected with the binding-post " $\mathrm{B}$," to which the necessary electrical connexions were made. The complication due to the sphericity of this surface is not so great as might be supposed, since the distances to be measured are of the order of a wave-length of light, whence a radius of curvature of $1 \cdot 26 \mathrm{~cm}$. is comparatively large.

The surface " $\mathrm{D}^{\prime}$ " consists of a brass disk ground plane, then heavily nickel-plated and polished. This was mounted on a movable carriage, "C," which bears the mirror, "M." The mirror $\mathrm{M}$ constitutes one arm of the interferometer. The surface $\mathrm{D}^{\prime}$ could thus be brought into contact with $\mathrm{D}$ by shifting the carriage. The point of contact was determined by means of a sensitive galvanometer with a small E.M.F. in circuit. The carriage having been pushed back until the point of contact was reached, the motion of the carriage was reversed; the distance through which it was moved could be ascertained by counting the number of fringes which passed during the displacement of the carriage.

The second condition imposed requires the measurement of differences of potential. In the experiments of Lord Kelvin and Liebig an absolute electrometer was used. The smallest difference in potential was approximately 2 C.G.S. units E.M.F. in the electrostatic system.

In this experiment the measurements of potential were made in the electromagnetic system, the readings being expressed in volts. The values obtained can therefore be transformed into electrostatic C.G.S. units by dividing by 300. A standard Weston voltmeter reading directly to volts was utilized in measuring the differences in potential. The instrument used was compared with a standard voltmeter recently calibrated by the Weston Company and kept in the laboratory for standardizing purposes.

Source of E.M.F.-The E.M.F. used was supplied by a 
hank of 2000 storage-cells so arranged that they might be used in units of 25 cells, or by special connexions of single cells. The cells were intended primarily for supplying small currents at high voltages, and had small capacity. It is highly desirable that small capacity be used ; otherwise, owing to the disruptive discharge, the surfaces would be greatly marred upon the passage of a spark.

Surfaces.-The surfaces as described above consist of one spherical surface and a plane surface. These were made optically perfect, free from scratches, and were polished with dry rouge. It is necessary, owing to pitting of the surfaces due to discharge, that a fresh surface be presented each time a reading is taken. This may be readily accomplished by rotating the bodies about an axis not in the line of symmetry. The means of accomplishing this will be apparent upon consulting figure 1 .

Method of Procedure.-The surfaces were brought into contact and separated by a distance considerably greater than a given difference of potential required for discharge. The number of fringes crossing the field during the displacement was noted. Call this number $a$. The potential was then established and the motion of the carriage reversed. The number of fringes of retrograde movement untii discharge occurred was noted. Call this number $b$. Then $\frac{a-b}{2}=$ distance in wave-lengths between plates, since the passage of a fringe corresponds to one-half wave-length displacement of the carriage. In fig. 2 , the plan of the electrical portion of the apparatus is indicated. $A s$ in fig. 1, D and $D^{\prime}$ represent the surfaces. These are connected to binding-posts $\mathrm{B}$ and $\mathrm{B}^{\prime}$. Circuit 1 contains the E.M.F., which may be varied from 2 volts to 5000 volts. Circuit 2 includes the voltmeter. Circuit 3 includes the galvanometer and small E.M.F. (about 1/100 voit) for determining the point of contact. All circuits are provided with suitable double-pole switches.

Atter the plates are separated, circuit 3 is opened, and a difference in potential between $D$ and $D^{\prime}$ established by closing circuit 1 . The voltmeter will register this potentialdifference. Upon the passage of a spark the resistance of the dielectric breaks down, causing a sudden drop in the potential existing between $\mathrm{D}$ and $\mathrm{D}^{\prime}$. Thus the voltmeter serves not only to measure differences in potential, but also. to detect the point where discharge occurs.

Before the readings the surfaces were polished with dry rouge, and freed from dust-particles by blowing them with iv jet of dust-free air. 
It was found that the apparent resistance of the dielectric depends in a measure upon the manner in which the potentialdifference is established. A sudden rise in potential trom zero up to a definite amount will cause a spark to jump

Figs. $1 \& 2$.
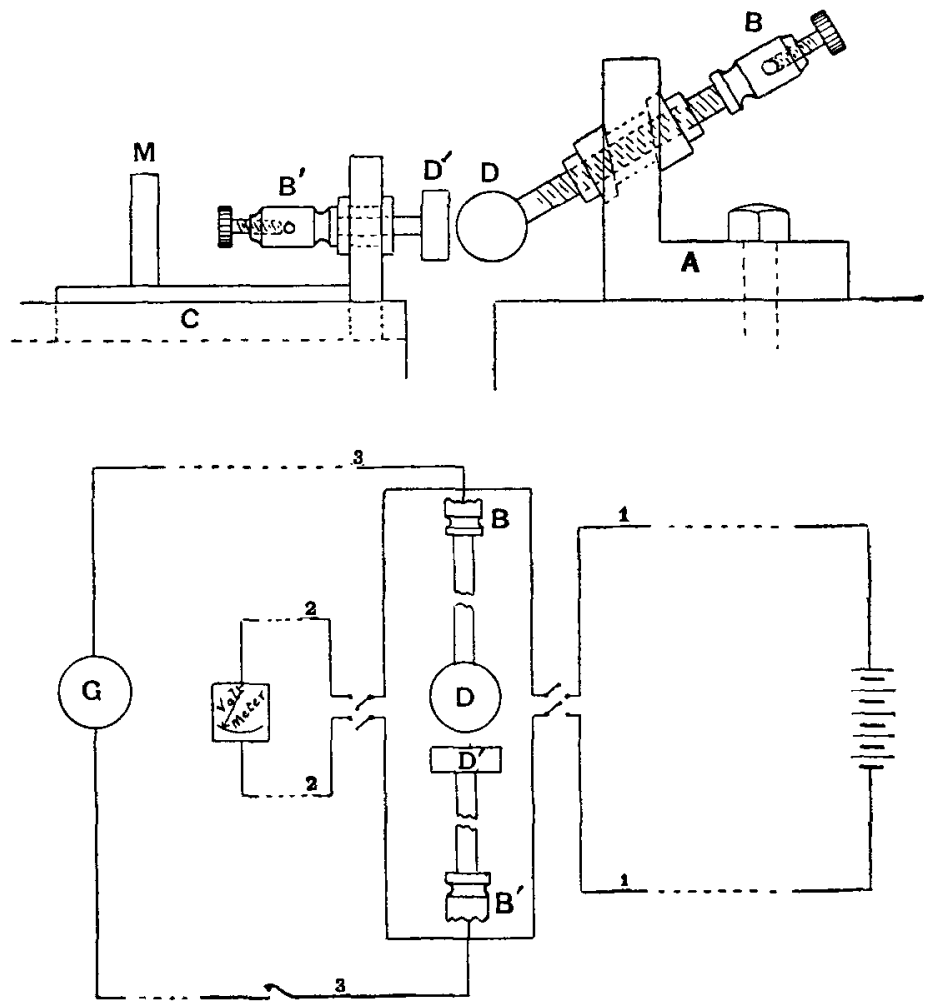

a considerably greater distance than if the potential were built up gradually. This is perhaps what might be expected ; for if we regard the energy due to the presence of the electrified bodies as existing as a strain in the separating medium, then the sudden application of such a strain would cause the medium to break down more readily than if the strain were applied gradually. The readings given in the table are those in which the potentials are buit up uradually, or, what amounts to the same thing, a given difference of potential being established, the plates were made to approach one another gradually, thus confining the strain to a more limited portion of the dielectric. It is for this reason that 
the plates were separated a greater distance than the potential seemed to require, and then gradually brought together.

Results. - Table I. and the corresponding curve designated I. (fig. 3) show the results from distances of $5 \lambda$ sodium light to $185 \lambda$, i.e. from $\cdot 3$ micron to 109 micra. In this case the dielectric was air under atmospheric pressure. The readings were taken during the winter months, and it was not deemed necessary to guard against water-vapour. The readings given in the following tables were taken in the spring and summer months, when the humidity is likely to be larger. In these cases the air was passed through suitable dryingtubes.

TABLe I.-Air, Atmospheric Pressure.

\begin{tabular}{|c|c|c|c|}
\hline $\begin{array}{c}\text { Distance in } \\
\text { Ware-lengths. }\end{array}$ & $\begin{array}{l}\text { Potential in } \\
\text { Volts. }\end{array}$ & $\begin{array}{c}\text { Distance in } \\
\text { Wave-lengths. }\end{array}$ & $\begin{array}{c}\text { Potential in } \\
\text { Volts. }\end{array}$ \\
\hline $\begin{array}{r}\cdot 5 \\
\cdot 7 \\
\cdot 7 \\
\cdot 8 \\
1 \cdot 0 \\
1 \cdot 0 \\
1 \cdot 2 \\
1 \cdot 3 \\
1 \cdot 5 \\
2 \cdot 0 \\
2 \cdot 5 \\
2 \cdot 5 \\
3 \cdot 0 \\
3 \cdot 0 \\
4 \cdot 0 \\
50 \\
5 \cdot 0 \\
8 \cdot 5 \\
13 \cdot 5 \\
14 \cdot 0\end{array}$ & $\begin{array}{r}38 \\
46 \\
52 \\
84 \\
100 \\
106 \\
108 \\
111 \\
152 \\
202 \\
240 \\
250 \\
300 \\
304 \\
312 \\
336 \\
344 \\
348 \\
350 \\
360\end{array}$ & 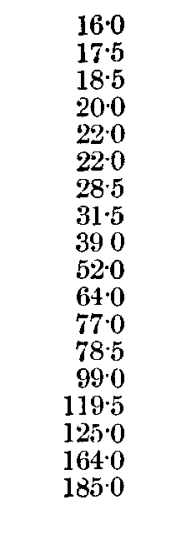 & $\begin{array}{r}360 \\
400 \\
408 \\
408 \\
416 \\
416 \\
454 \\
460 \\
512 \\
556 \\
604 \\
664 \\
670 \\
712 \\
820 \\
864 \\
986 \\
1080\end{array}$ \\
\hline
\end{tabular}

From the results indicated in Curve I. (fig. 3) it will be observed that from readings from 5 to 3 wave-lengths the potential required for discharge varies directly with the distance. Between wave-lengths 3 and 4 the curve takes a sudden bend, and proceeds in nearly a straight line, varying with the distance, but according to a different law. If we accept the hypothesis of an air-film surrounding the surfaces of the bodies, the sudden variation in the form of the curve between wave-lengths 3 and 4 would seem to be another argument in its favour, and would indicate the thickness of such a film as being $1 \cdot 5 \lambda$ sodium light, i. e. about $\cdot 9 \mu$.

It is of some interest to compare the portions of the curve indicated with those given by previous observers. The obser- 
between Plates for small Distances.

Fig. 3.

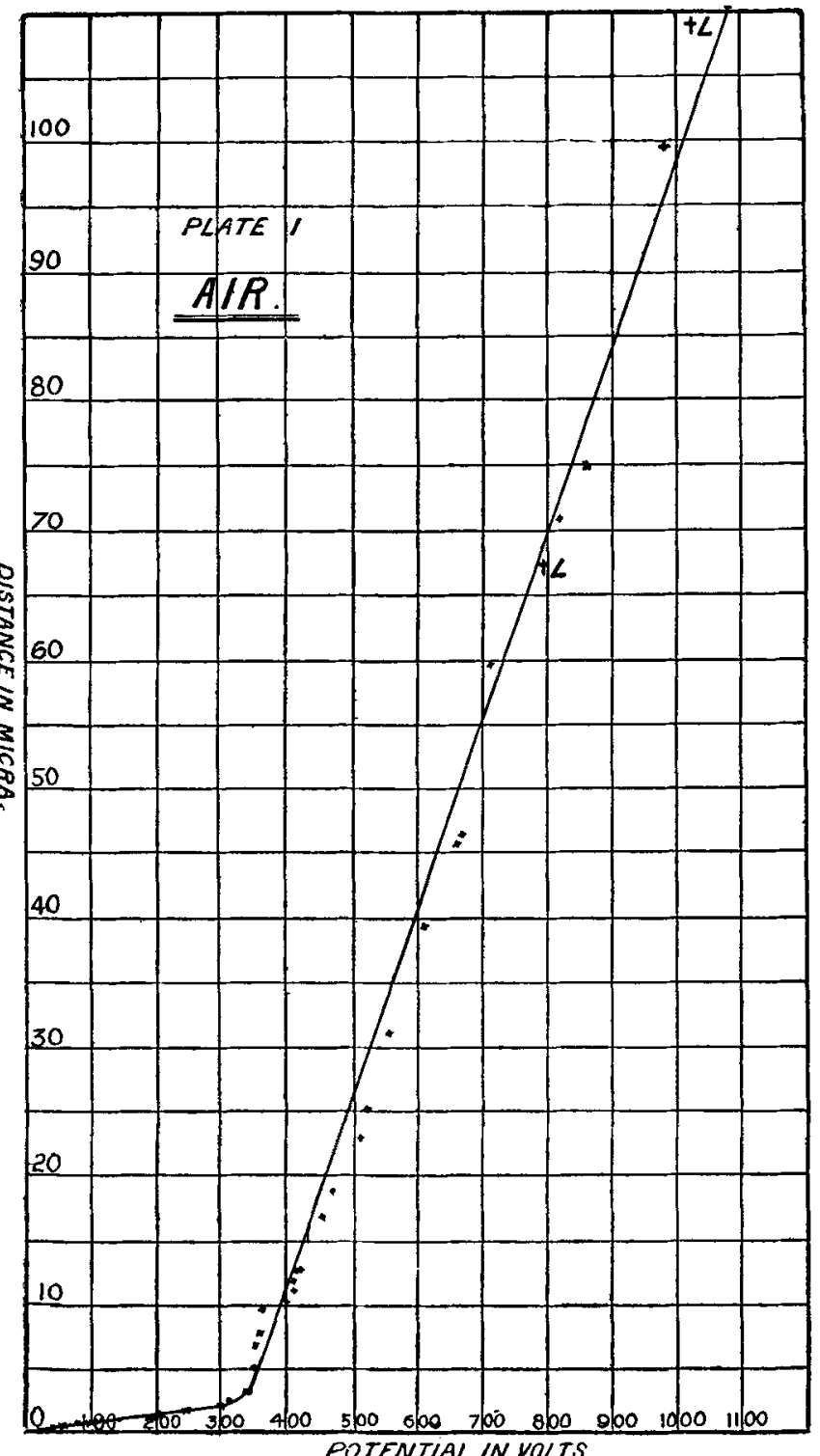


vations of Dr. Liebig, previously mentioned in this article, are perhaps more complete for relatively large distances than those given in any published table. Dr. Liebig has two values which fall within the limit of this experiment. Reducing his observations to the scale here used, they show a very close agreement. They are indicated in fig. 3 by a dagger, together with the letter $\mathrm{L}$.

Effect of Pressure.-Tables II. to V. indicate the values obtained for the pressures indicated. These results are represented graphically in fig. 4. The values obtained indicate that for varying pressures the general form of the curve is the same as that under atmospheric pressure, but that after passing a certain limiting distance, the second straight portion of the curve makes a different angle with the $\mathrm{X}$-axis, the inclination depending on the pressure. For pressures greater than one atmosphere, values of the potential up to a distance of three wave-lengths seem to coincide very closely with the values given for one atmosphere. After passing this "turning-point," the curve again becomes a straight line. For pressures less than one atmosphere the values indicate that, in the first straight portion of the curve, a smaller potential is required to cause the spark to pass a given distance. The character of the curve would lead us to believe that for very low exhaustions the resistance of the air-film, if such does exist, becomes much weakened, and that for minute pressures we should have a curve lying close along the $\mathrm{Y}$-axis. The discharge through a Geissler tube is probably of this character.

In obtaining the readings under pressure other tban one atmosphere, the entire instrument was enclosed in an iron box provided with suitable windows. The movement of the

TABLI: II.-Air, $40 \mathrm{~cm}$. Pressure.

\begin{tabular}{|c|c|c|c|}
\hline $\begin{array}{c}\text { Distance in } \\
\text { Wave-lengths. }\end{array}$ & $\begin{array}{l}\text { Potential in } \\
\text { Vulis. }\end{array}$ & $\begin{array}{c}\text { Distance in } \\
\text { Wave-lengths. }\end{array}$ & $\begin{array}{l}\text { Potential in } \\
\text { Volts. }\end{array}$ \\
\hline $\begin{array}{l}1.0 \\
1.5 \\
1.5 \\
2.0 \\
2.5 \\
2.5 \\
3.0 \\
4.0 \\
4.5 \\
5 \cdot 0 \\
5.5\end{array}$ & $\begin{array}{r}52 \\
75 \\
82 \\
104 \\
146 \\
150 \\
152 \\
170 \\
204 \\
304 \\
320\end{array}$ & $\begin{array}{r}15 \cdot 0 \\
19 \cdot 0 \\
21 \cdot 0 \\
33.5 \\
40 \cdot 5 \\
54.0 \\
67.0 \\
750 \\
1.500 \\
178.5\end{array}$ & $\begin{array}{l}328 \\
356 \\
360 \\
412 \\
464 \\
496 \\
552 \\
592 \\
660 \\
720\end{array}$ \\
\hline
\end{tabular}


between Plates for small Distances.

TABLE III.-Air, $15 \mathrm{~cm}$. Pressure.

\begin{tabular}{|c|c||c|c|}
\hline $\begin{array}{c}\text { Distance in } \\
\text { Wave-lengths. }\end{array}$ & $\begin{array}{c}\text { Potential in } \\
\text { Volts. }\end{array}$ & $\begin{array}{c}\text { Distance in } \\
\text { Wave-lengths. }\end{array}$ & $\begin{array}{c}\text { Potential in } \\
\text { Volts. }\end{array}$ \\
\hline 1.5 & 85 & $29 \cdot 0$ & \\
$2 \cdot 5$ & 106 & $53 \cdot 5$ & 320 \\
$3 \cdot 0$ & 122 & $78 \cdot 0$ & 360 \\
$4 \cdot 0$ & 156 & 103.5 & 400 \\
60 & 200 & $160 \cdot 0$ & 412 \\
8.0 & 300 & $200 \cdot 0$ & 468 \\
& & 512 \\
\hline
\end{tabular}

TAble IV.-Air, Two Atmospheres Pressure.

\begin{tabular}{|c|c||c|c|}
\hline $\begin{array}{c}\text { Distance in } \\
\text { Wave-lengths. }\end{array}$ & $\begin{array}{c}\text { Potential in } \\
\text { Volts. }\end{array}$ & $\begin{array}{c}\text { Distance in } \\
\text { Wave-lengths. }\end{array}$ & $\begin{array}{c}\text { Potential in } \\
\text { Volts. }\end{array}$ \\
\hline $1 \cdot 0$ & 96 & $17 \cdot 0$ & 460 \\
$1 \cdot 5$ & 130 & $19 \cdot 5$ & 508 \\
$1 \cdot 5$ & 142 & $25 \cdot 0$ & 564 \\
$2 \cdot 0$ & 200 & $29 \cdot 5$ & 684 \\
$3 \cdot 0$ & 302 & $36 \cdot 0$ & 720 \\
$4 \cdot 5$ & 312 & $45 \cdot 0$ & 840 \\
$5 \cdot 5$ & 324 & $45 \cdot 0$ & 912 \\
$6 \cdot 0$ & 356 & $47 \cdot 0$ & 880 \\
95 & 376 & $55 \cdot 0$ & 1016 \\
$14 \cdot 0$ & 376 & & \\
\hline
\end{tabular}

Table V.-Air, Three Atmospheres Pressure.

\begin{tabular}{|c|c||c|c|}
\hline $\begin{array}{c}\text { Distance in } \\
\text { Wave-lengths. }\end{array}$ & $\begin{array}{c}\text { Potential in } \\
\text { Volts. }\end{array}$ & $\begin{array}{c}\text { Distance in } \\
\text { Wave-lengtbs. }\end{array}$ & $\begin{array}{c}\text { Potential in } \\
\text { Volts. }\end{array}$ \\
\hline $1 \cdot 0$ & 107 & $15 \cdot 0$ & 512 \\
$2 \cdot 0$ & 194 & $17 \cdot 0$ & 512 \\
$2 \cdot 5$ & 240 & $19 \cdot 0$ & 568 \\
$2 \cdot 5$ & 260 & 245 & 660 \\
$3 \cdot 0$ & 304 & $31 \cdot 5$ & 768 \\
$8 \cdot 0$ & 368 & $38 \cdot 0$ & 886 \\
$11 \cdot 5$ & 500 & $42 \cdot 0$ & 1024 \\
$13 \cdot 0$ & 480 & & \\
\hline
\end{tabular}

plates was controlled by a tangent-screw working through a stuffing-box.

\section{Carbon Dioxide.}

The only other gas experimented upon was $\mathrm{CO}_{2}$. The gas was allowed to pass into the iron vessel described in the previous paragraph, the air being removed by displacement. The results obtained are given in Tables VI. and VII., and represented graphically in fig. 5. Both curves are for $\mathrm{CO}_{2}$ under atmospheric pressure, with this distinction: that in the upper branch of the curve a gentle flow of $\mathrm{CO}_{2}$ was 
156 Mr. R. F. Earbart on the Sparking Iistances

Fig. 4.

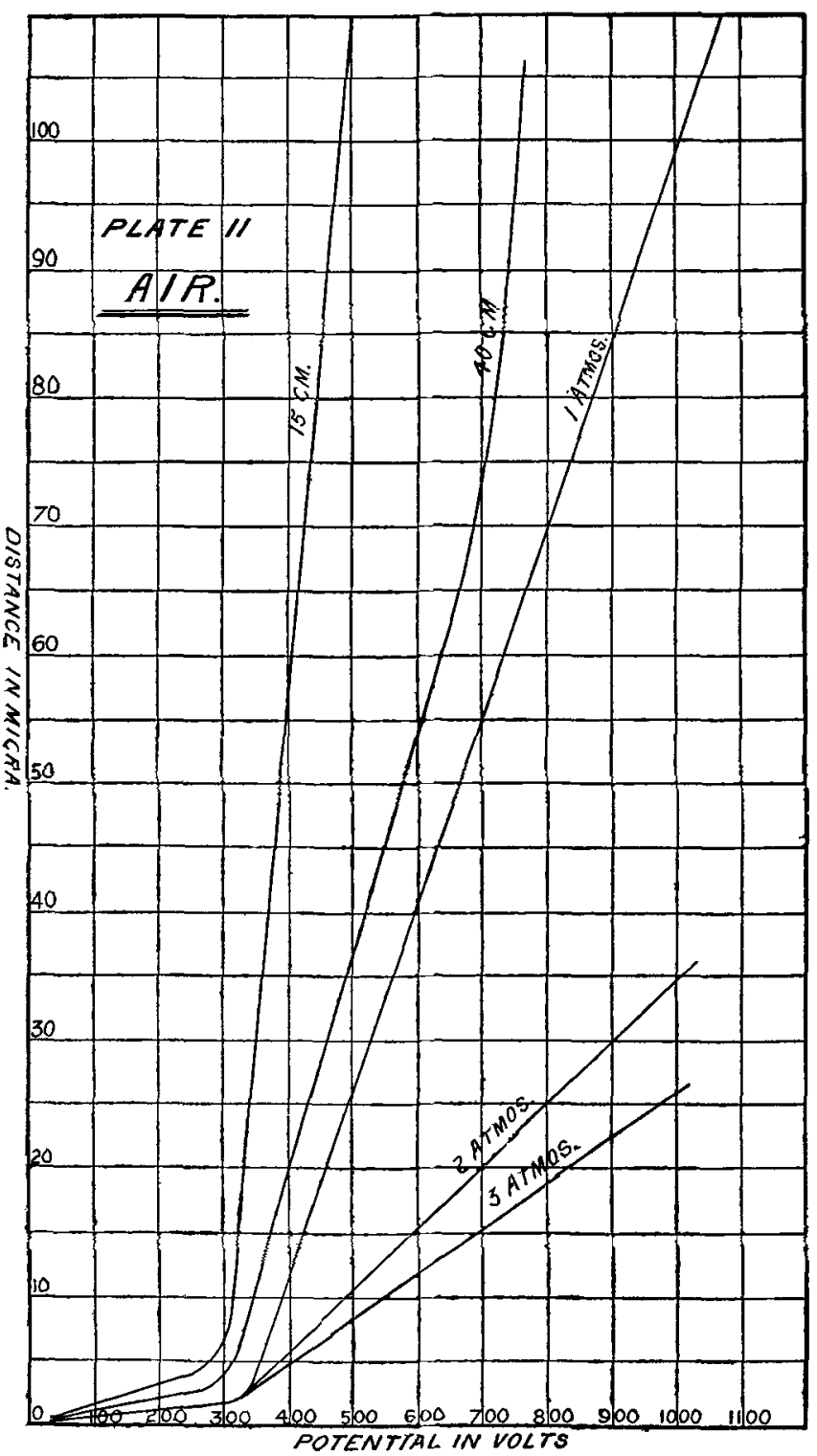


between Plates for small Distances.

TABLE VI.-Carbon Dioxide (surface blown).

\begin{tabular}{|c|c||c|c|}
\hline $\begin{array}{c}\text { Distance in } \\
\text { Wave-lengths. }\end{array}$ & $\begin{array}{c}\text { Potential in } \\
\text { Volts. }\end{array}$ & $\begin{array}{c}\text { Distance in } \\
\text { Wave-lengths. }\end{array}$ & $\begin{array}{c}\text { Potential in } \\
\text { Volts. }\end{array}$ \\
\hline $1 \cdot 0$ & 100 & & \\
$1 \cdot 5$ & 150 & $9 \cdot 5$ & 364 \\
$1 \cdot 5$ & 182 & $22 \cdot 0$ & 412 \\
$2 \cdot 0$ & 250 & $31 \cdot 5$ & 408 \\
$2 \cdot 5$ & 250 & $36 \cdot 0$ & 420 \\
$2 \cdot 5$ & 300 & $52 \cdot 5$ & 480 \\
$3 \cdot 0$ & 300 & $62 \cdot 0$ & 560 \\
$4 \cdot 0$ & 304 & $93 \cdot 0$ & 592 \\
4.5 & 340 & $110 \cdot 0$ & 630 \\
$5 \cdot 5$ & 360 & $125 \cdot 0$ & 736 \\
$9 \cdot 0$ & 376 & & 780 \\
\hline
\end{tabular}

TABLE VII.-Carbon Dioxide (surface not blown).

\begin{tabular}{|c|c||c|c|}
\hline $\begin{array}{c}\text { Distance in } \\
\text { Wave-lengths. }\end{array}$ & $\begin{array}{c}\text { Potential in } \\
\text { Volts. }\end{array}$ & $\begin{array}{c}\text { Distance in } \\
\text { Wave-lengths. }\end{array}$ & $\begin{array}{c}\text { Potential in } \\
\text { Volts. }\end{array}$ \\
\hline $1 \cdot 0$ & 104 & $17 \cdot 0$ & 568 \\
$2 \cdot 0$ & 212 & $18 \cdot 5$ & 582 \\
$2 \cdot 5$ & 260 & $30 \cdot 5$ & 618 \\
$3 \cdot 0$ & 300 & $38 \cdot 5$ & 660 \\
$3 \cdot 5$ & 320 & $52 \cdot 5$ & 678 \\
$4 \cdot 5$ & 360 & $77 \cdot 5$ & 732 \\
$5 \cdot 0$ & 412 & $84 \cdot 0$ & 768 \\
$7 \cdot 5$ & 464 & $107 \cdot 0$ & 870 \\
$12 \cdot 0$ & 516 & & \\
\hline
\end{tabular}

maintained over the surfaces, while for the lower branch the gas was quiescent. This distinction gave rise at first to what appeared to be inconsistent readings, but the apparent wide discrepancy in the readings was found to be due to the cause indicated below. In the case of the gas in motion, a jet of $\mathrm{CO}_{2}$ was allowed to impinge on the contact-surfaces; not, however, at the point where contact would take place, but remote from the region of contact : thus it was hoped to secure a gentle flow of the gas, which would naturally spread out over the surfaces. The values from which the lower limb of the curve were obtainer were those taken after the $\mathrm{CO}_{2}$ had filled the box and the supply had been cut off. The readings were taken in from two to four minutes after the box was filled. The separate readings are indicated for the upper curve (surface blown) by a cross $(x)$. The readings for the lower curve (surface not blown) by a circle $(o)$. As an explanation of the two branches of the curve I submit the following hypothesis:-We know from general. 
158 Sparking Distances between Plates for small Distances.

considerations, such as the pressing together of parallel plates, various experiments with a coherer, that an air-film is tenacious. In the case of the upper curve this air-film remains intact, but the $\mathrm{CO}_{2}$, having displaced the body of Fio. 5.

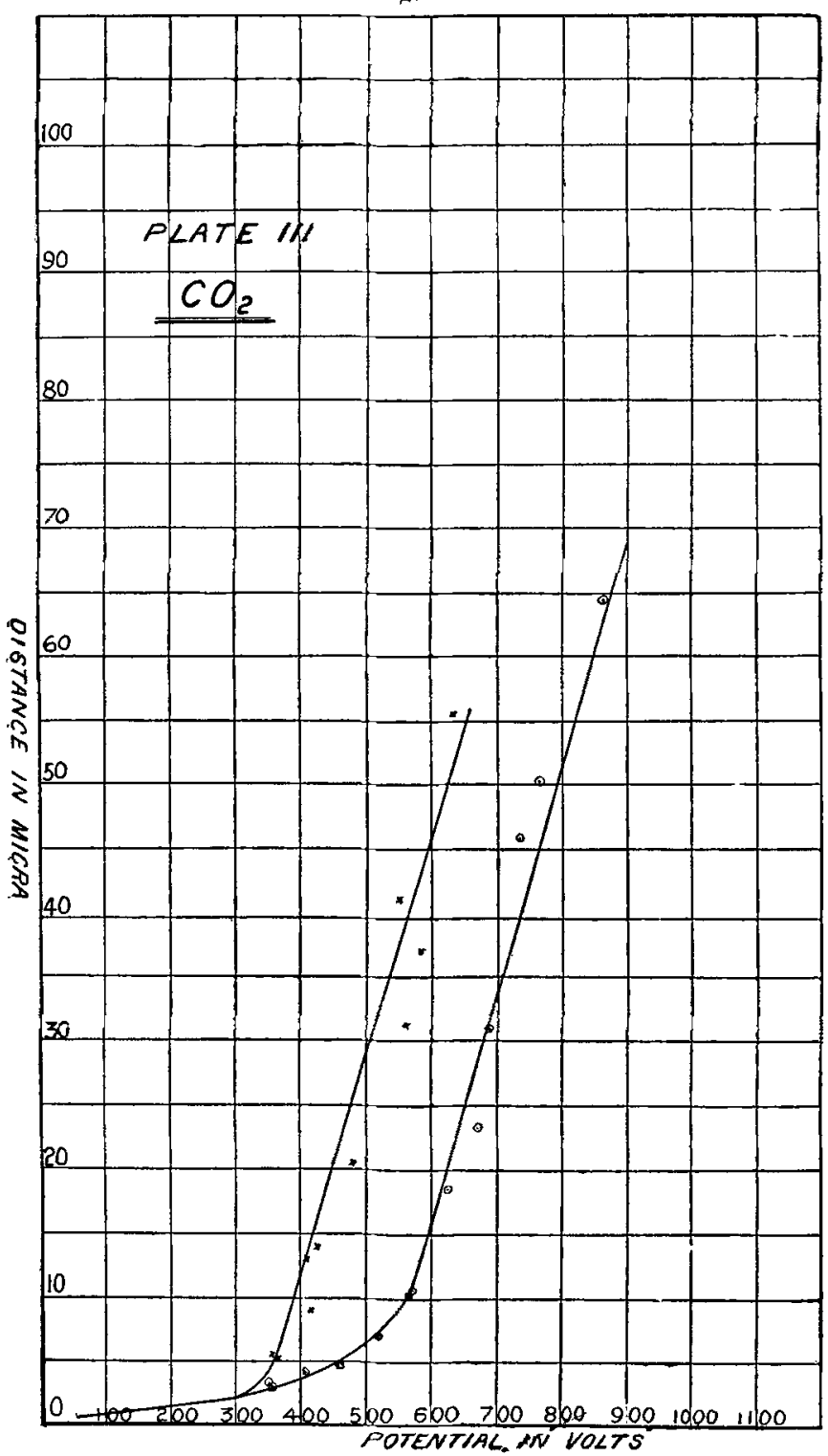


air, furnishes the remaining resistance. When the gas is flowing across this surface the molecules of the gas are too greatly agitated, too much stirred by convection-currents, to group themselves into anything like the semblance of a film. In the cuse of a gas quiescent, the $\mathrm{CO}_{2}$ meeting a limiting surface and not being disturbed, a film of carbon dioxide forms, which is superposed over the air-film. The fact that the upper portions of both branches are parallel indicates that they differ, in this region at least, by an additive constant. Several readings taken after the $\mathrm{CO}_{2}$ had remained in the vessel for about thirty minutes, seemed to indicate a greater resistance of the dielectric for a given distance. It seems probable that a time-factor enters into this consideration. The readings, however, are too few in number to base any further statement thereon.

In conclusion, it becomes my pleasure to thank Prof. A. A. Michelson not only for suggesting this experiment, but for encouragement and advice always freely given throughout the course of the work. It is also my pleasure to thank Prof. S. W. Stratton for many courtesies rendered during the progress of this experiment.

Ryerson Laboratory,

University of Chicago.

Sept. 13th, 1900.

XII. On the Refraction of Sound by Wind. By EDwIN H. Barton, D.Sc., F.R.S.E., Senior Lecturer in Physics at University College, Nottingham*.

$T^{\mathrm{N}}$ his treatise on Sound (vol. ii. pp. 132-4), Lord Rayleigh 1 discusses the refraction of sound by wind where the rays are everywhere but slightly inclined to the wind, and obtains an approximate expression which, in the numerical illustration adduced, gives a result differing by only a few minutes of arc from the strict value. The theoretical interest of the wave propagation in this case seems, however, to warrant a slightly fuller examination of the problem on the basis of Huyghens's principle of wavelets and envelopes. Let us retain Lord Rayleigh's assumption as to the distribution of the wind, namely, that it is everywhere horizontal and does not vary in any one horizontal plane but is different at different levels. Then, confining our examination to rays in the same vertical plane as the wind, we find the following results :-

(1) The direction of propagation is not usually at right angles to the wave-front where there is a wind, consequently the cosecant law for the wave-front needs

* Communicated by the Physical Society : read Nor. 9, 1900. 